\title{
Chinese medicine Ginseng and Astragalus granules ameliorate autoimmune diabetes by upregulating both CD4+FoxP3+ and CD8+CD122+PD1 + regulatory T cells
}

\author{
Yeshu Wang ${ }^{1, *}$, Qingfeng Xie ${ }^{2, *}$, Chun-Ling Liang ${ }^{3, *}$, Qiaohuang Zeng ${ }^{1}$ and Zhenhua \\ $\mathrm{Dai}^{3}$ \\ ${ }^{1}$ Graduate School, Guangzhou University of Chinese Medicine, Guangzhou, Guangdong, P.R. China \\ ${ }^{2}$ Center for Regenerative and Translational Medicine, Guangdong Provincial Academy of Chinese Medical Sciences, Guangdong \\ Provincial Hospital of Chinese Medicine, Guangzhou, Guangdong, P.R. China \\ ${ }^{3}$ Section of Immunology, Guangdong Provincial Academy of Chinese Medical Sciences, Guangzhou, Guangdong, P.R. China \\ *These authors have contributed equally to this work \\ Correspondence to: Zhenhua Dai, email: zdai2009@outlook.com \\ Keywords: autoimmunity, type 1 diabetes, regulatory $T$ cells, Chinese medicine \\ Abbreviations: CsA, cyclosporine; GAG, ginseng and astragalus granule; T1DM, type 1 diabetes mellitus; Treg, regulatory T cell \\ Received: March 21, $2017 \quad$ Accepted: April 27, $2017 \quad$ Published: June 27, 2017 \\ Copyright: Wang et al. This is an open-access article distributed under the terms of the Creative Commons Attribution License 3.0 \\ (CC BY 3.0), which permits unrestricted use, distribution, and reproduction in any medium, provided the original author and source \\ are credited.
}

\section{ABSTRACT}

Type 1 diabetes mellitus (T1DM) is an autoimmune disease mainly mediated by effector $T$ cells that are activated by autoantigen, thereby resulting in the destruction of pancreatic islets and deficiency of insulin. Cyclosporine is widely used as an immunosuppressant that suppresses autoimmunity in clinic. However, continuous treatments with conventional immunosuppressive drugs may cause severe side effects. Therefore it is important to seek alternative medicine. Chinese medicine Ginseng and Astragalus granule (GAG) was used to successfully treat type 2 diabetes mellitus in clinic in China. Here we found that GAG ameliorated T1DM in autoimmune NOD mice by increasing the level of insulin and reducing the level of blood glucose. Treatments with both GAG and CsA further decreased the blood glucose level. Moreover, GAG increased both CD4+FoxP3+ and CD8+CD122+PD-1+ Treg numbers in both spleens and lymph nodes of NOD mice. In particular, GAG could reverse a decline in CD4+FoxP3+ Tregs resulted from CsA treatments. The percentage of effector/memory CD8+ T cells (CD44 ${ }^{\text {high }}$ CD62 L $^{\text {low }}$ ) was significantly reduced by GAG, especially in the presence of low-doses of CsA. Histopathology also showed that GAG attenuated cellular infiltration and lowered CD3+ T cell numbers around and in islets. Thus, we demonstrated that GAG ameliorated autoimmune T1DM by upregulating both CD4+FoxP3+ and CD8+CD122+PD-1+ Tregs while GAG synergized with CsA to further suppress autoimmunity and T1DM by reversing the decline in CD4+FoxP3+ Tregs resulted from CsA treatments. This study may have important clinical implications for the treatment of T1DM using traditional Chinese medicine.

\section{INTRODUCTION}

Type 1 diabetes mellitus (T1DM) is an autoimmune disease mainly mediated by effector $\mathrm{T}$ lymphocytes that are activated by an autoantigen and then destroy pancreatic islets, thereby resulting in the deficiency of insulin production $[1,2]$. Regulatory $\mathrm{T}$ cells (Treg), a subset of $\mathrm{T}$ cells that can suppress autoimmune reactions, play a crucial role in sustaining autoimmune tolerance and preventing autoimmune diseases. However, its number and function were shown to be quite low in some autoimmune diseases, such as T1DM [3-8]. On the other hand, effector 
T cells play an important role in both humoral and cellular immune responses as traditionally aggressive T cells. An imbalance between Tregs and autoreactive effector $\mathrm{T}$ cells in favor of the effector cells could result in the onset of various autoimmune diseases.

Treatments of T1DM are dependent on long-term injection of insulin when pancreatic islets are totally destroyed although immunosuppressive agents could reverse T1DM during the early stage of the disease. However, it may require continuous treatments with a conventional immunosuppressant that usually causes side effects. Traditional Chinese medicine Ginseng and Astragalus granules (GAG), mainly composed of Ginseng and Astragalus, is widely used to treat type 2 diabetes mellitus in China [9, 10]. GAG contains 10 herbs, including Ginsenosides, Schisandra, Astragalus, Yam, Radix rehmanniae, Ophiopogon japonicus, Poria, Radix trichosanthis, Rhizoma alismatis and Chinese wolfberry. Previous studies have also demonstrated that GAG significantly ameliorates hyperglycemia, increases blood insulin levels, and improves the glucose tolerance through enhancing islet cell function [11]. However, it is unknown whether GAG can be utilized to treat T1DM and suppress autoimmune responsiveness.

Here, we examined the effects of Chinese medicine GAG on the onset of T1DM in female NOD mice. We found that administration of GAG decreased the level of blood glucose but elevated blood insulin level of NOD mice. Importantly, administering both GAG and low doses of CsA further ameliorated autoimmune T1DM compared with treatments with either GAG or CsA alone. Moreover, GAG augmented both CD4+FoxP3+ and CD8+CD122+PD1+ Tregs in spleens and lymph nodes of NOD mice. In particular, it was capable of increasing CD4+FoxP3+ Tregs even in the presence of CsA.

\section{RESULTS}

\section{GAG significantly decreases the level of blood glucose in T1DM-prone NOD mice}

We determined whether GAG, which was widely used to treat type 2 diabetes mellitus, could also have an impact on type 1 diabetes mellitus (T1DM). GAG was administered by oral gavage at $3 \mathrm{~g} / \mathrm{kg} / \mathrm{d}$ while CsA was injected intraperitoneally at $7.5 \mathrm{mg} / \mathrm{kg} / \mathrm{d}$ to threemonths old female NOD mice daily for eight weeks. As shown in Figure 1A, we found that GAG alone obviously increased the level of blood insulin eight weeks after the treatments. Similar findings were seen at the time point of four weeks (Data not shown). On the other hand, GAG alone decreased blood glucose level while CsA alone also did the same (Figure 1B). However, the best result was brought by the combination of GAG and CsA, which further reduced the blood glucose level compared with either GAG alone or CsA alone.

\section{GAG induces both CD4+FoxP3+ and CD8+CD122+PD-1+ Tregs even in the presence of low-doses of CsA}

We next examined if GAG could ameliorate T1DM by up-regulating Tregs, especially in the presence of CsA, which has been shown to suppress CD4+FoxP3+ Treg development. Spleen and lymph node cells were isolated from female NOD mice following GAG and/ or CsA treatments, and the percentage of CD4+FoxP3+ and CD8+CD122+PD-1+ Tregs was determined by FACS analyses eight weeks after treatments. As shown in Figure 2A, GAG significantly increased the percentage of CD8+CD122+PD-1+ Tregs in both lymph nodes and
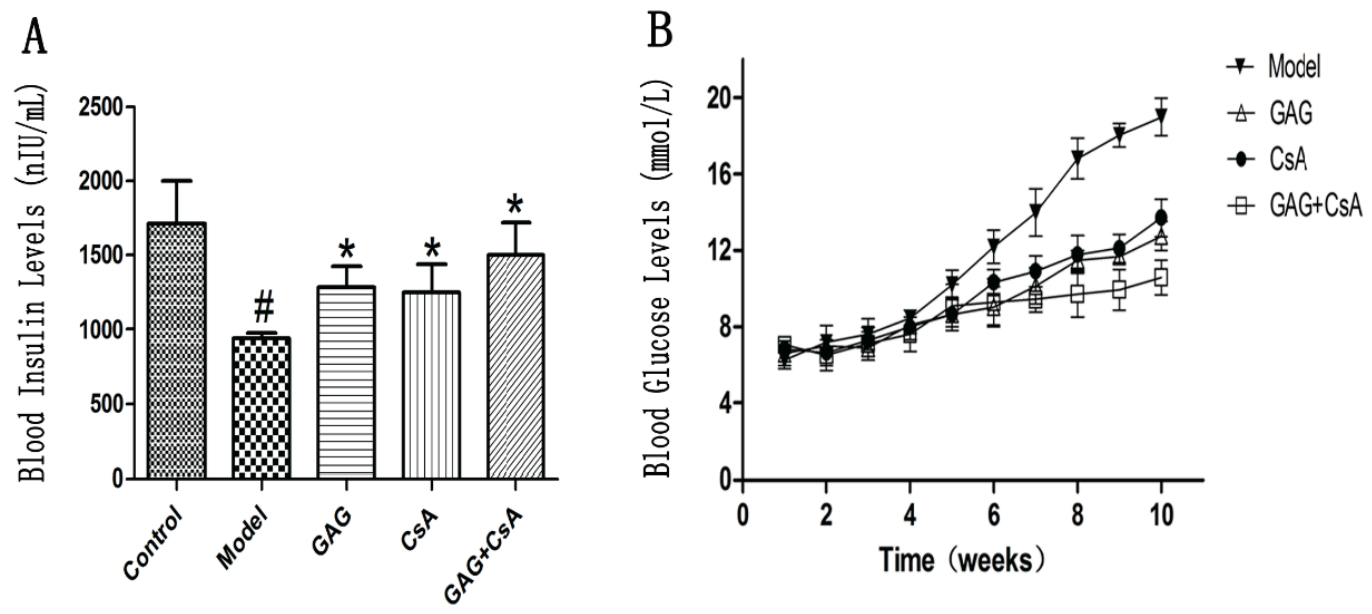

Figure 1: GAG significantly increases blood insulin but decreases blood glucose level. Three months-old female NOD mice were treated with GAG and/or CsA for eight weeks, and then the blood insulin level was detected by ELISA (A). The values of blood glucose were also detected using Opitima Xceed and Test Strips weekly for ten weeks after the first treatment with GAG (B). Data are presented as Mean $\pm \mathrm{SD}(\mathrm{n}=4$ - 5 mice/group). One representative of two independent experiments is shown (\# represents comparison with Control; and * represents comparison with Model, both $\mathrm{p}<0.05$ ). 
spleens of NOD mice in the absence or presence of CsA when compared with CsA alone or Model control. Moreover, as shown in Figure 2B, GAG also increased the percentage of CD4+FoxP3+ Tregs in both lymph nodes and spleens of NOD mice compared to Model group. As expected, CsA significantly reduced their percentage in both locations. Importantly, GAG was able to increase CD4+FoxP3+ Tregs even in the presence of CsA, suggesting a perfect synergy between GAG and CsA.
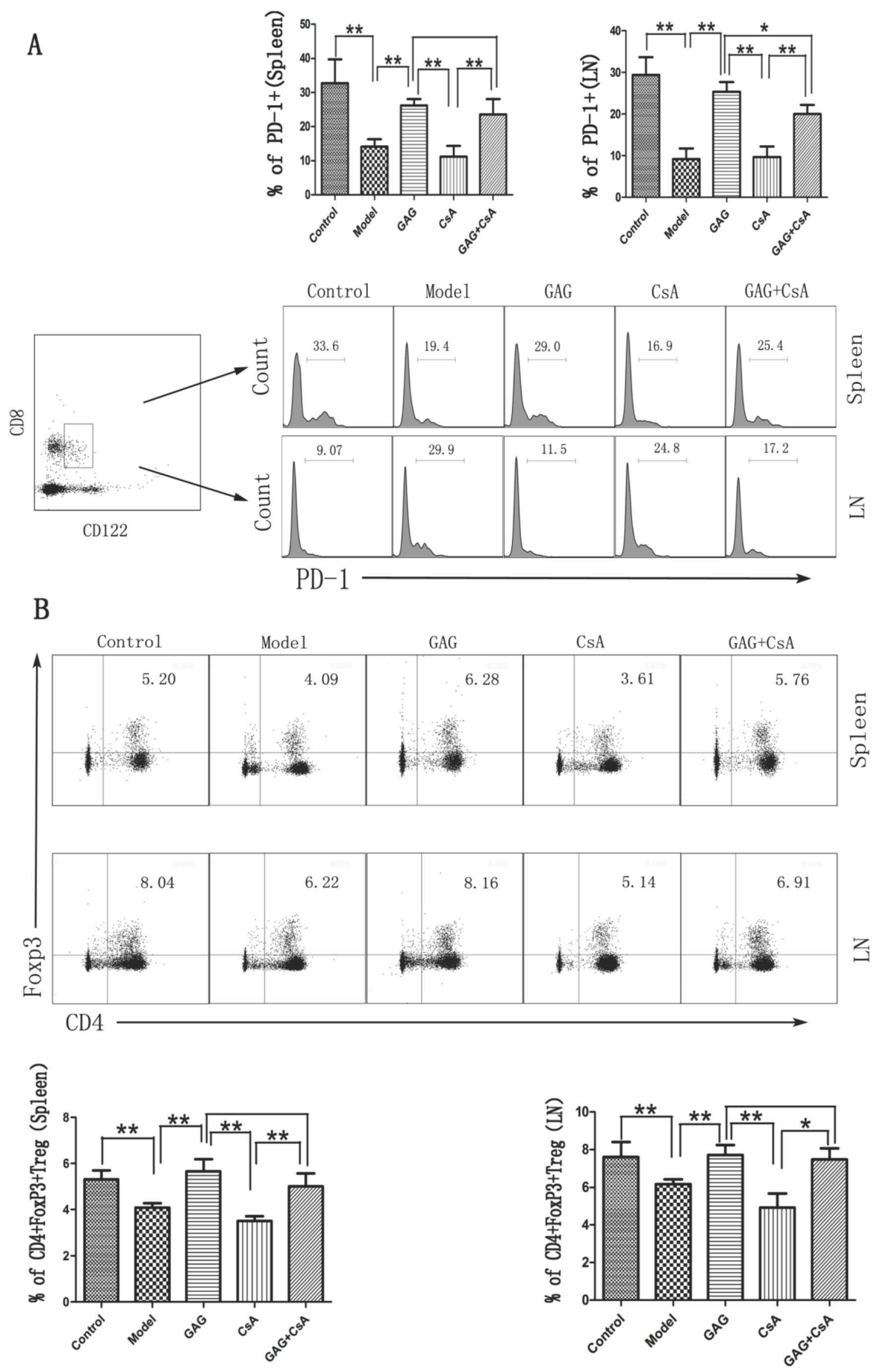

Figure 2: GAG induces both CD8+CD122+PD-1+ and CD4+FoxP3+ Tregs in NOD mice. Spleen and lymph node cells were isolated from female NOD mice eight weeks after treatments with GAG and/or CsA, then stained for cell surface markers: CD8, CD122, and PD-1 to detect CD8+CD122+PD-1+ Tregs (A). To quantify CD4+FoxP3+ Tregs, CD4 surface marker was first stained, and then intracellular marker FoxP3 was done (B). PD-1 histogram was gated on CD8+CD122+ cells. One representative of three separate FACS data is shown $(* \mathrm{p}<0.05$ and $* * \mathrm{p}<0.01)$. 


\section{GAG reduces the number of effector $T$ cells $\left(T_{\text {eff }}\right)$ in NOD mice}

Since GAG was able to attenuate T1DM in NOD mice, we measured if GAG would influence the effector $\mathrm{T}$ cell differentiation. Spleen cells and lymph node cells derived from GAG-treated NOD mice were stained for surface markers CD8, CD44 and CD62L, and the percentage of $\mathrm{CD} 8+\mathrm{CD} 44+\mathrm{CD} 62 \mathrm{~L}^{\text {low }}$ cells was determined by FACS analyses eight weeks post-treatment. As shown in Figure 3, GAG significantly decreased the proportion of CD8+CD44+CD62L Low cells. In particular, treatments with both GAG and CsA further reduced the percentage of $\mathrm{CD} 8+\mathrm{CD} 44+\mathrm{CD} 62 \mathrm{~L}^{\text {low }}$ cells compared to $\mathrm{GAG}$ or CsA alone, indicating their synergistically suppressive effects on autoimmune T1DM.

\section{GAG hinders the infiltration of T lymphocytes in pancreas and alleviates the damage of pancreatic islet cells}

To visulize cellular infiltration and insulin expression in pancreatic tissues, we isolated the pancreases of NOD mice after eight weeks of treatments with GAG and/or CsA, and fixed them in 4\% neutral formaldehyde. $\mathrm{HE}$ staining and immunohistochemical staining of CD3 and insulin were performed on paraffin-embedded tissue sections. As shown in Figure 4, the cellular infiltration, as shown by HE staining, in the group of GAG was obviously weakened compared to the Model group while CsA also reduced the cellular infiltration. GAG plus CsA further attenuated the cellular infiltration. Similarly, either GAG or CsA reduced the numbers of $\mathrm{CD} 3+\mathrm{T}$ cells while $\mathrm{GAG}$ plus CsA further decreased their numbers. However, GAG or CsA alone increased insulin expression in pancreatic islets compared to the Model group while GAG plus CsA further enhanced the expression of insulin, suggesting that GAG or CsA alleviates the functional damage of islet cells.

\section{GAG significantly increases IL-10 but decreases IL-17 level in the content of pancreases of NOD mice}

Since GAG was anti-inflammatory and could alleviate cellular infiltration in pancreases, we finally asked if GAG could exert its effects via regulating cytokines such as IL-10 and IL-17. After eight weeks of treatments with GAG and/or CsA, pancreatic tissue was homogenized and the supernatant was collected to detect these two cytokines by ELISA. As shown in Figure 5, the level of pro-inflammatory cytokine IL-17 was significantly
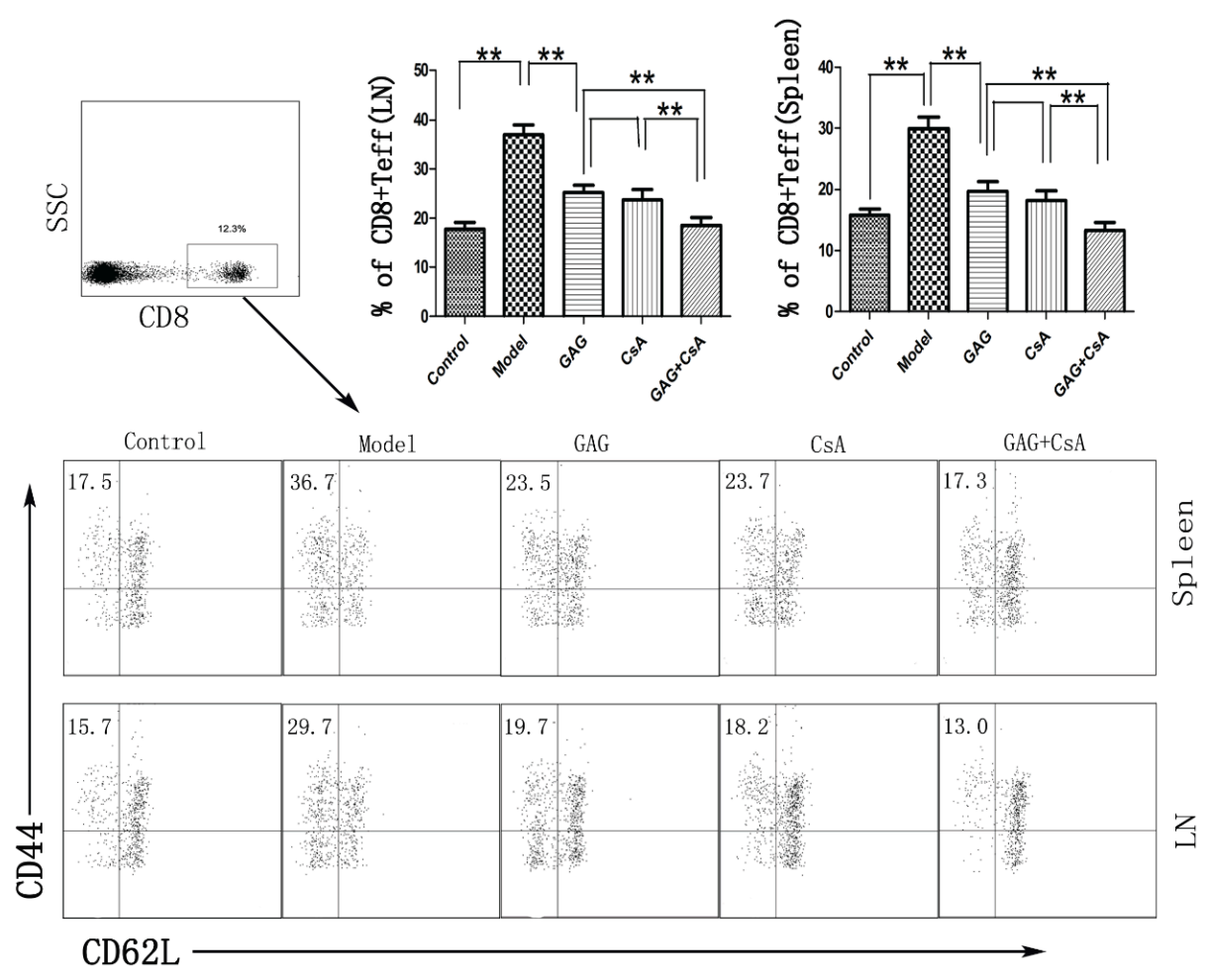

Figure 3: GAG shrinks effector CD8+ $\mathbf{T}$ cell $\left(\mathbf{T}_{\text {eff }}\right)$ pool in NOD mice. Spleen and lymph node cells were isolated from female NOD mice that were treated with GAG and/or CsA for eight weeks. Cells were then stained for CD8, CD44, CD62L surface markers. The dot plots for CD44 and CD62L were gated on CD8+ subset. One representative of three separate FACS data is shown $\left({ }^{*} \mathrm{p}<0.05\right.$ and $* * \mathrm{p}<0.01)$. 
reduced by GAG or CsA, especially when the combination of GAG and CsA was administered, while antiinflammatory cytokine IL-10 was significantly increased by GAG and/or CsA. These findings suggest that GAG regulates autoimmunity and indeed is immunosuppressive.

\section{DISCUSSION}

Using T1DM-prone NOD mice as readout to observe suppression of autoimmunity by Chinese medicine, we examined the effects of Chinese herbal formula GAG on the onset of T1DM in female NOD mice. We demonstrated that administration of GAG decreased the level of blood glucose but elevated the blood insulin level in NOD mice over time. Importantly, administering both GAG and low doses of CsA further ameliorated autoimmune T1DM compared with treatments with either GAG alone or CsA alone. Furthermore, GAG augmented both CD4+FoxP3+ and CD8+CD122+PD1+ Tregs in spleens and lymph nodes of NOD mice. In particular, GAG increased CD4+FoxP3+ Tregs even in the presence of CsA, which otherwise would hinder their generation. GAG also increased IL-10 but lowered IL-17 level in the content of pancreatic tissues of NOD mice. This finding may have clinical implications for the treatment of T1DM, especially in the early stage of the disease.

Conventional immunosuppressive agents, including CsA, may suppress autoimmunity and alleviate autoimmune diseases when administered during the early stage of the disease. However, patients with autoimmune

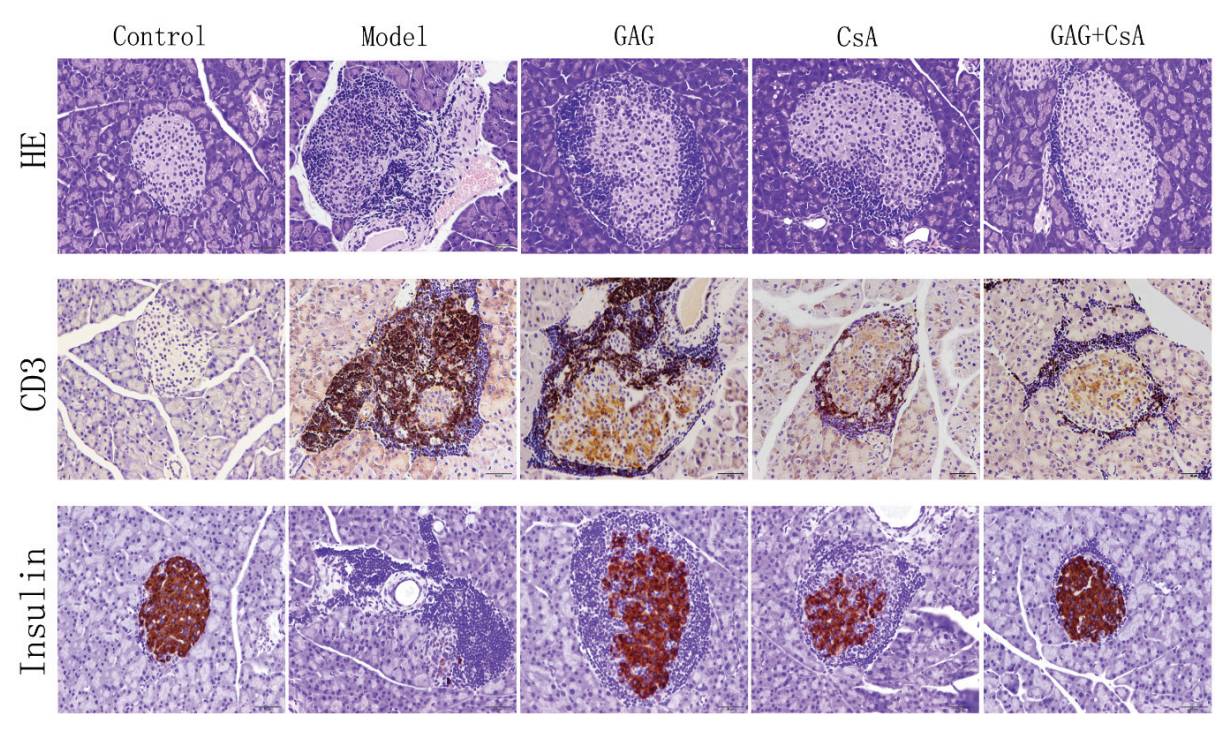

Figure 4: GAG and CsA significantly alleviate the infiltration of CD3+ $T$ cells and general cellular infiltration in pancreatic islets. Pancreases of NOD mice were collected eight weeks after treatments with GAG and/or CsA, and fixed in 4\% neutral formaldehyde. Then paraffin-embedded tissues were stained with hematoxylin and eosin (HE) as well as anti-CD3 and anti-insulin mAbs for IHC. One representative of two sets of imaging is shown (Amplification: x200).
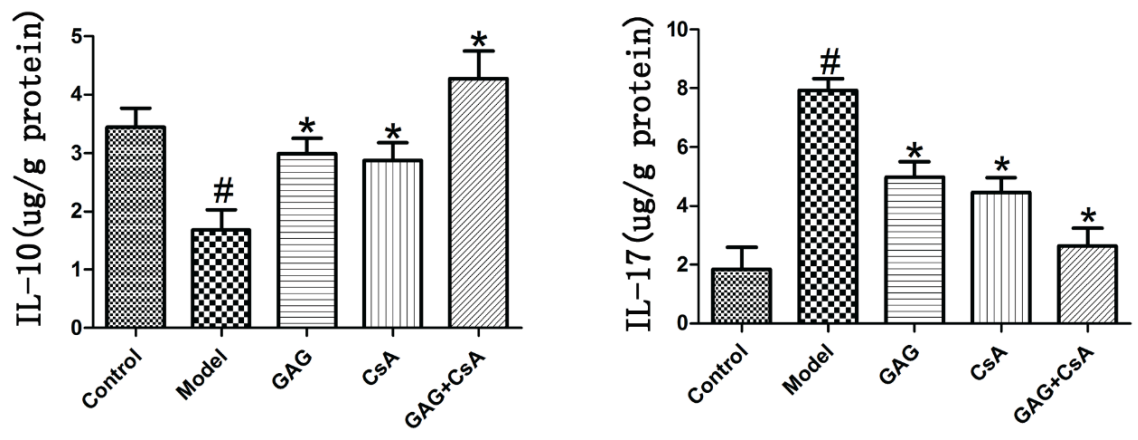

Figure 5: GAG up-regulates the level of IL-10 but down-regulates the level of IL-17. After eight weeks of treatments of NOD mice with GAG and/or CsA, pancreatic tissue was homogenized and the supernatant was collected to detect two cytokines IL-10 and IL17 via ELISA. We utilized $\mu \mathrm{g} / \mathrm{g}$ (protein) as the unit to express its content in the tissue. One representative of two separate experiments is shown. (\# represents comparison with Control; and * represents comparison with Model, both p<0.05). 
diseases need continuous treatments with a conventional immunosuppressant that usually causes various side effects. Generally speaking, traditional Chinese medicine is believed to cause only moderate side effects. Ginseng and Astragalus granule (GAG), largely composed of Ginseng and Astragalus, has been widely used to treat type 2 diabetes mellitus in China [9, 10]. Previous studies have also demonstrated that GAG significantly ameliorates hyperglycemia, increases blood insulin level, and improves the glucose tolerance in animals with type 2 diabetes [11]. Here we found that GAG could also ameliorate autoimmune T1DM in NOD mice, which may lay the groundwork for clinical trials using GAG to treat T1DM in humans.

CD4+CD25+ regulatory $\mathrm{T}$ (Treg) cells play a key role in the maintenance of immune tolerance to both self- and foreign-antigens by suppressing aggressive $\mathrm{T}$ cell responses. These Tregs represent a small fraction $(5-10 \%)$ of $\mathrm{CD} 4+\mathrm{T}$ cells and constitutively express the $\alpha$ chain of the IL-2 receptor (CD25) [12-14]. The induction of endogenous CD4+CD25+ Tregs or adoptive transfer of exogenous Tregs prevents autoimmune diseases and allograft rejection in many animal models [15-22]. Recently, mounting evidence has demonstrated that $\mathrm{CD} 8+\mathrm{CD} 122+\mathrm{T}$ cells are also Tregs that inhibit conventional $\mathrm{T}$ cell responses [23-28], antitumor immunity [29], as well as autoimmunity [30, 31]. We have previously shown that $\mathrm{CD} 8+\mathrm{CD} 122+\mathrm{T}$ cells are not only Tregs $[32,33]$, but also are more potent in suppression of allograft rejection than conventional CD4+CD25+ Tregs [34]. In particular, we previously have demonstrated that PD-1-positive component within $\mathrm{CD} 8+\mathrm{CD} 122+\mathrm{T}$ cell population is mainly responsible for their regulatory activities while antigen-specific CD8+CD122+PD-1- T cells are true memory T cells [32]. Therefore, CD8+CD122+ Tregs likely correspond to their CD4+CD25+ counterparts since CD122 is the $\beta$ subunit of IL-2 receptor on T cells while CD25 is the $\alpha$ subunit of the same receptor [12], suggesting that both subsets of Tregs may cooperate to maintain the immunologic homeostasis and to keep autoimmune responses in check.

In this study, we found that GAG augmented both CD4+FoxP3+ and CD8+CD122+PD1+ Tregs in T1DMprone NOD mice. Since GAG simultaneously increased both CD4+FoxP3+ and CD8+CD122+PD1+ Tregs, these two subsets of Tregs likely cooperated to exert their suppressive effects [28]. In particular, GAG increased traditional CD4+FoxP3+ Tregs even in the presence of CsA, indicating a much-needed synergy between GAG and CsA. Previous studies have shown that CsA is detrimental to the survival and function of Tregs via impeding the expression of IL-2 [35-37], which is crucial to Treg development. Moreover, CsA can suppress both generation and function of CD4+CD25+FoxP3+ Tregs in both mice and human beings [38-41]. Although CsA hinders generation and function of Tregs, it is still widely used to effectively treat patients with many of the autoimmune diseases. Therefore, combination of CsA and GAG is an ideal approach to maintaining the capacity of CsA to suppress autoimmune responses while sparing Tregs by GAG treatments. Our findings will establish a good example for treating autoimmune diseases using joint treatments with traditional Chinese medicine and Western medicine.

In conclusion, traditional Chinese medicine GAG, which effectively treats type 2 diabetes in clinic, can also alleviate autoimmune T1DM in NOD mice by upregulating both $\mathrm{CD} 4+\mathrm{FoxP} 3+$ and CD8+CD122+PD1+ Tregs. It also plays a regulatory role in controlling autoimmune responses by reducing IL-17 production in the pancreatic tissue given that IL-17 is critically involved in autoimmunity $[42,43]$. Moreover, GAG regulates autoimmunity by increasing immunosuppressive cytokine IL-10. Since it increases both CD4+FoxP3+ and CD8+CD122+PD1+ Tregs as well as IL-10 production, an increase in IL-10 level is likely attributed to augmentation in both Tregs that in turn produce IL-10. Thus, in addition to type 2 diabetes, T1DM may also be treated using traditional Chinese medicine GAG. Our results have clinical implications.

\section{MATERIALS AND METHODS}

\section{Mice and reagents}

NOD mice were purchased from Beijing HFK Bioscience CO., LTD (Beijing, China). All mice were housed in a specific pathogen-free environment and all animal experiments were approved by the Institutional Animal Care and Use Committee. Traditional Chinese medicine formula, Ginseng and Astragalus granule (GAG), composed of Ginsenosides of it's stem and leaves, Schisandra, Astragalus, Yam, Radix rehmanniae, Ophiopogon japonicus, Poria, Radix trichosanthis, Rhizoma alismatis and Chinese wolfberry, was purchased from Lunan Houpu Pharmaceutical Co. Ltd (Lunan, China). Cyclosporin A (CsA) was purchased from the Guangdong Provincial Hospital of Traditional Chinese Medicine (Guangzhou, China). Anti-CD4-PE, anti-Foxp3APC, anti-CD8-PE, anti-CD44-PE-Cy5, anti-CD62LFITC, anti-CD8-FITC, anti-CD122-PE, and anti-PD-1APC mAbs were purchased from BD Biosciences (BD Biosciences, San Jose, CA) or eBioscience (eBioscience, San Diego, CA).

\section{Treatments of mice}

Female NOD mice were housed in a specific pathogen-free environment. When they were three months old, their random blood glucose levels were detected using Opitima Xceed and Test Strips (Abbott) once a week. GAG was dissolved in normal saline and orally 
administered at $3 \mathrm{~g} / \mathrm{kg} /$ day to three-months-old NOD mice daily for eight weeks. Meanwhile, cyclosporin A was also diluted in normal saline and administered i.p. at $7.5 \mathrm{mg} / \mathrm{kg} /$ day while normal saline was used as controls (Model). After eight weeks' treatments, we continued to observe their condition and monitor their blood glucose etc. for two additional weeks. In addition to control groups treated with normal saline (Model group) versus GAG (GAG group), at the end of treatments when samples were collected, we used three-months old healthy NOD mice without any treatment as normal controls.

\section{Intracellular staining and flow analyses}

Draining lymph nodes and spleen cells were isolated four and eight weeks after treatments. First, cells were stained for surface markers with anti-CD4-PE, anti-CD8PE, anti-CD44-PE-Cy5, anti-CD62L-FITC anti-CD8FITC, anti-CD122-FITC, or anti-PD-1-APC, separately in some samples, and then intracellular markers in some groups with anti-FoxP3-APC using intracellular fixation/ permeabilization kit (eBioscience, San Diego, CA). CD4+Foxp3+ Tregs, CD8+CD122+PD-1+Tregs, and effecter T cells were enumerated by FACS analyses.

\section{Measurement of insulin and cytokines}

Peripheral blood was collected and stored at room temperature for 30 minutes, then centrifuged at $3000 \mathrm{xg}$ for 20 minutes to collect the serum, and the insulin was detected using the ELISA kit (CUSABIO, Wuhan, China) according to the manufacturer's instructions. As for the interleukin-10 (IL-10) and interleukin-17 (IL-17), about $50 \mathrm{mg}$ tissue was homogenized in 500ul precooled PBS to produce the mixture, which was then centrifuged at $5000 \mathrm{xg}$ at $4^{\circ} \mathrm{C}$ for 5 minutes. The supernatant was collected, and then we detected the total protein of the supernatant by Pierce ${ }^{\mathrm{TM}}$ BCA Assaay Kit (Thermo Fisher Scientific, Massachusetts, USA). Finally, IL-10 and IL-17 in the supernatant were detected by ELISA kits (BOSTER, Wuhan, China). The unit of $\mu \mathrm{g} / \mathrm{g}$ (protein) was utilized to express the content of both cytokines in the tissue.

\section{Hematoxylin-Eosin (HE) and Immunohistochemical (IHC) staining}

Pancreatic tissues were fixed in 4\% neutral formaldehyde for 24-48 hours, and embedded in paraffin, then cut into 3-4 $\mu \mathrm{m}$ sections. The sections were dried at $55^{\circ} \mathrm{C}$, then deparaffinized in Xylen, followed by dehydration through the graded alcohol. Some tissue sections were only stained with hematoxylin and eosin. Moreover, endogenous peroxidase activity was blocked by $3 \% \mathrm{H}_{2} \mathrm{O}_{2}$. The sections were then incubated with primary monoclonal anti-CD3 and anti-insulin antibodies (Abcam, Cambridge, UK) at $4^{\circ} \mathrm{C}$ over night. After incubation with HRP-anti-mouse $\operatorname{IgG}$, sections were colored using 3'3'-diaminobenzidene (DAB, Sigma-Aldrich) and counterstained by Hematoxylin.

\section{Statistical analysis}

Comparisons of the mean were performed using the Student $t$-test for two groups and ANOVA for multiple groups. All analyses were performed using Prism-6 software (GraphPad Software, La Jolla, CA). Data were presented as Mean $\pm \mathrm{SD}$. A value of $\mathrm{P}<0.05$ was considered statistically significant.

\section{ACKNOWLEDGMENTS}

We thank Mr. Wanlin Yu for his assistance in FACS analysis.

\section{CONFLICTS OF INTEREST}

The authors of this manuscript have no any conflicts of interest to disclose.

\section{GRANT SUPPORT}

This study was supported by a joint grant from Guangdong Provincial Department of Science \& Technology and Guangdong Provincial Academy of Chinese Medical Sciences (2014A020221053).

\section{REFERENCES}

1. Bach JF, Chatenoud L. A historical view from thirty eventful years of immunotherapy in autoimmune diabetes. Semin Immunol. 2011; 23:174-181.

2. Steck AK, Rewers MJ. Genetics of type 1 diabetes. Clin Chem. 2011; 57:176-185.

3. Ellis JS, Braley-Mullen H. Mechanisms by Which B Cells and Regulatory T Cells Influence Development of Murine Organ-Specific Autoimmune Diseases. Journal of clinical medicine. 2017; 6 .

4. Trehanpati N, Vyas AK. Immune regulation by T regulatory cells in HBV related Inflammation and cancer. Scandinavian journal of immunology. 2017.

5. Sakaguchi S. Naturally arising CD4+ regulatory t cells for immunologic self-tolerance and negative control of immune responses. Annual review of immunology. 2004; 22:531-562.

6. Sakaguchi S, Ono M, Setoguchi R, Yagi H, Hori S, Fehervari Z, Shimizu J, Takahashi T, Nomura T. Foxp3+ $\mathrm{CD} 25+\mathrm{CD} 4+$ natural regulatory $\mathrm{T}$ cells in dominant selftolerance and autoimmune disease. Immunological reviews. 2006; 212:8-27.

7. Sakaguchi S, Sakaguchi N. Regulatory $\mathrm{T}$ cells in immunologic self-tolerance and autoimmune disease. International reviews of immunology. 2005; 24:211-226. 
8. Sakaguchi S, Setoguchi R, Yagi H, Nomura T. Naturally arising Foxp3-expressing CD25+CD4+ regulatory T cells in self-tolerance and autoimmune disease. Curr Top Microbiol Immunol. 2006; 305:51-66.

9. Rao XM, Chen BK. Clinical observation of 32 patients of type 2 diabetes treated with Ginseng and Astragalus granule Xin Lin Zhong Yi Yao. 2004; 24:23-25.

10. Liu WW, Shi SZ, Lin YH. 90 cases of patients with type 2 diabetes treated with Ginseng and Astragalus granule. [Article in Chinese]. Jiangxi Zhong Yi Yao. 2008; 39:27-29.

11. Zhou XL, Sun YX. Effects of Ginseng and Astragalus granule on beta cell function and glucose tolerance. [Article in Chinese]. Zhong Guo Zhong Yi Ji Zhen. 2006; 15:369-370.

12. Sakaguchi S, Sakaguchi N, Asano M, Itoh M, Toda M. Immunological self-tolerance maintained by activated $\mathrm{T}$ cells expressing IL-2 receptor alpha-chains (CD25)breakdown of a single mechanism of self-tolerance causes various autoimmune diseases. J Immunol. 1995; 155:1151-1164.

13. Read S, Malmstrom V, Powrie F. Cytotoxic T lymphocyteassociated antigen 4 plays an essential role in the function of $\mathrm{CD} 25+\mathrm{CD} 4+$ regulatory cells that control intestinal inflammation. J Exp Med. 2000; 192:295-302.

14. Takahashi T, Tagami T, Yamazaki S, Uede T, Shimizu J, Sakaguchi N, Mak TW, Sakaguchi S. Immunologic self-tolerance maintained by $\mathrm{CD} 25+\mathrm{CD} 4+$ regulatory $\mathrm{T}$ cells constitutively expressing cytotoxic $\mathrm{T}$ lymphocyteassociated antigen 4. J Exp Med. 2000; 192:303-309.

15. Asano M, Toda M, Sakaguchi N, Sakaguchi S. Autoimmune disease as a consequence of developmental abnormality of a T cell subpopulation. J Exp Med. 1996; 184:387-396.

16. Suri-Payer E, Amar A, Thornton A, Shevach E. $\mathrm{CD} 4+\mathrm{CD} 25+\mathrm{T}$ cells inhibit both induction and effector function of autoreactive $\mathrm{T}$ cells and represent a unique lineage of immunoregulatory cells. J Immunol. 1998; 160:1212-1218.

17. Itoh M, Takahashi T, Sakaguchi N, Kuniyasu Y, Shimizu J, Otsuka F, Sakaguchi S. Thymus and Autoimmunity: Production of CD25+CD4+ Naturally Anergic and Suppressive T Cells as a Key Function of the Thymus in Maintaining Immunologic Self-Tolerance. J Immunol. 1999; 162:5317-5326.

18. Zhai Y, Kupiec-Weglinski JW. What is the role of regulatory $\mathrm{T}$ cells in transplantation tolerance? Curr Opin Immunol. 1999; 11:497-503.

19. Shevach EM. Regulatory T cells in autoimmunity. Annu Rev Immunol. 2000; 18:423-449.

20. Qin S, Cobbold S, Pope H, Elliott J, Kioussis D, Davies J, Waldmann H. "Infectious" transplantation tolerance. Science. 1993; 259:974-977.

21. Hoffmann P, Ermann J, Edinger M, Fathman CG, Strober S. Donor-type CD4+CD25+ regulatory $\mathrm{T}$ cells suppress lethal acute graft-versus-host disease after allogeneic bone marrow transplantation. J Exp Med. 2002; 196:389-399.
22. Fu S, Yopp AC, Mao X, Chen D, Zhang N, Chen D, Mao M, Ding Y, Bromberg JS. CD4+ CD25+ CD62+ T-regulatory cell subset has optimal suppressive and proliferative potential. Am J Transplant. 2004; 4:65-78.

23. Rifa'i M, Kawamoto Y, Nakashima I, Suzuki H. Essential roles of CD8+CD122+ regulatory T cells in the maintenance of T cell homeostasis. J Exp Med. 2004; 200:1123-1134.

24. Endharti AT, Rifa IM, Shi Z, Fukuoka Y, Nakahara Y, Kawamoto Y, Takeda K, Isobe K, Suzuki H. Cutting edge: $\mathrm{CD} 8+\mathrm{CD} 122+$ regulatory $\mathrm{T}$ cells produce IL-10 to suppress IFN-gamma production and proliferation of CD8+ T cells. $\mathrm{J}$ Immunol. 2005; 175:7093-7097.

25. Chen X, Priatel JJ, Chow MT, Teh HS. Preferential development of CD4 and CD8 T regulatory cells in RasGRP1-deficient mice. J Immunol. 2008; 180:5973-5982.

26. Shi Z, Rifa'i M, Lee YH, Shiku H, Isobe K, Suzuki H. Importance of $\mathrm{CD} 80 / \mathrm{CD} 86-\mathrm{CD} 28$ interactions in the recognition of target cells by $\mathrm{CD} 8+\mathrm{CD} 122+$ regulatory $\mathrm{T}$ cells. Immunology. 2008; 124:121-128.

27. Molloy MJ, Zhang W, Usherwood EJ. Suppressive CD8+ $\mathrm{T}$ cells arise in the absence of CD4 help and compromise control of persistent virus. J Immunol. 2011; 186:6218-6226.

28. Endharti AT, Okuno Y, Shi Z, Misawa N, Toyokuni S, Ito $\mathrm{M}$, Isobe K, Suzuki H. CD8+CD122+ regulatory T cells (Tregs) and CD4+ Tregs cooperatively prevent and cure CD4+ cell-induced colitis. J Immunol. 2011; 186:41-52.

29. Wang LX, Li Y, Yang G, Pang PY, Haley D, Walker EB, Urba WJ, Hu HM. CD122+CD8+ Treg suppress vaccineinduced antitumor immune responses in lymphodepleted mice. Eur J Immunol. 2010; 40:1375-1385.

30. Kim HJ, Wang X, Radfar S, Sproule TJ, Roopenian DC, Cantor H. CD8+ T regulatory cells express the Ly49 Class I MHC receptor and are defective in autoimmune prone B6-Yaa mice. Proc Natl Acad Sci U S A. 2011; 108:2010-2015.

31. Mangalam AK, Luckey D, Giri S, Smart M, Pease LR, Rodriguez M, David CS. Two discreet subsets of CD8 $\mathrm{T}$ cells modulate PLP(91-110) induced experimental autoimmune encephalomyelitis in HLA-DR3 transgenic mice. J Autoimmun. 2012; 38:344-353.

32. Dai H, Wan N, Zhang S, Moore Y, Wan F, Dai Z. Cutting edge: programmed death-1 defines CD8+CD122+ T cells as regulatory versus memory $\mathrm{T}$ cells. J Immunol. 2010; 185:803-807.

33. Liu J, Chen D, Nie GD, Dai Z. CD8(+) CD122(+) T-Cells: A Newly Emerging Regulator with Central Memory Cell Phenotypes. Front Immunol. 2015; 6:494.

34. Dai Z, Zhang S, Xie Q, Wu S, Su J, Li S, Xu Y, Li $\mathrm{XC}$. Natural CD8+CD122+ $\mathrm{T}$ cells are more potent in suppression of allograft rejection than CD4+CD25+ regulatory T cells. Am J Transplant. 2014; 14:39-48. 
35. Kang HG, Zhang D, Degauque N, Mariat C, Alexopoulos S, Zheng XX. Effects of cyclosporine on transplant tolerance: the role of IL-2. Am J Transplant. 2007; 7:1907-1916.

36. Zeiser R, Nguyen VH, Beilhack A, Buess M, Schulz S, Baker J, Contag CH, Negrin RS. Inhibition of CD4+CD25+ regulatory T-cell function by calcineurin-dependent interleukin-2 production. Blood. 2006; 108:390-399.

37. Noris M, Casiraghi F, Todeschini M, Cravedi P, Cugini D, Monteferrante G, Aiello S, Cassis L, Gotti E, Gaspari F, Cattaneo D, Perico N, Remuzzi G. Regulatory T cells and T cell depletion: role of immunosuppressive drugs. J Am Soc Nephrol. 2007; 18:1007-1018.

38. Wang H, Zhao L, Sun Z, Sun L, Zhang B, Zhao Y. A potential side effect of cyclosporin A: inhibition of CD4(+) CD25(+) regulatory T cells in mice. Transplantation. 2006; 82:1484-1492.

39. Baan CC, van der Mast BJ, Klepper M, Mol WM, Peeters AM, Korevaar SS, Balk AH, Weimar W. Differential effect of calcineurin inhibitors, anti-CD25 antibodies and rapamycin on the induction of FOXP3 in human T cells. Transplantation. 2005; 80:110-117.

40. Shibutani S, Inoue F, Aramaki O, Akiyama Y, Matsumoto K, Shimazu M, Kitajima M, Ikeda Y, Shirasugi N, Niimi M. Effects of immunosuppressants on induction of regulatory cells after intratracheal delivery of alloantigen. Transplantation. 2005; 79:904-913.

41. Lim DG, Koo SK, Park YH, Kim Y, Kim HM, Park CS, Kim SC, Han DJ. Impact of immunosuppressants on the therapeutic efficacy of in vitro-expanded CD4+CD25+Foxp3+ regulatory $\mathrm{T}$ cells in allotransplantation. Transplantation. 2010; 89:928-936.

42. Awasthi A, Murugaiyan G, Kuchroo VK. Interplay between effector Th17 and regulatory T cells. J Clin Immunol. 2008; 28:660-670.

43. Marwaha AK, Leung NJ, McMurchy AN, Levings MK. TH17 Cells in Autoimmunity and Immunodeficiency: Protective or Pathogenic? Front Immunol. 2012; 3:129. 